\title{
The Mystery behind "Yawning": A Physiological Insight
}

\author{
Dipak Kumar Dhar ${ }^{1}$ Ritik Arora ${ }^{2}$ \\ 1Department of Physiology, Himalayan Institute of Medical \\ Sciences, Swami Rama Himalayan University, Jolly Grant, \\ Dehradun, Uttarakhand, India \\ ${ }^{2}$ Himalayan Institute of Medical Sciences, Swami Rama Himalayan \\ University, Jolly Grant, Dehradun, Uttarakhand, India
}

\begin{abstract}
Address for correspondence Dipak Kumar Dhar, MD, Department of Physiology, Himalayan Institute of Medical Sciences, Swami Rama Himalayan University, Jolly Grant, Dehradun 248140, Uttarakhand, India (e-mail: dkdharagmc@gmail.com).
\end{abstract}

J Health Allied Sci NU:2020;10:57-62

\begin{abstract}
Keywords

- yawning

- mirror neuron system

- arousal

Yawning is a very ubiquitous yet very poorly understood phenomenon. Even though with advancements in science, the scientific community has been able to decode the mechanisms and mysteries behind most of the physiological functions of the body, but we still do not have clear answers to this common activity that all of us experience numerous times on a daily basis. It is the enigma surrounding yawning that makes it all more intriguing. A lot of hypotheses and theories have been proposed since the times of Hippocrates. With more modern neuroimaging methods and bioassays available now, more meticulous inquiry is being increasingly made to elucidate a rational and scientifically sound physiological basis of yawning. A comprehensive and exhaustive study of articles and research work available on the internet on the subject was made through various search engines such as Google Scholar, PubMed, etc. This article attempts to provide in a nutshell the available information and knowledge on the subject and discuss its plausibility and the future direction of research in this field.
\end{abstract}

\section{Introduction}

Yawning is a ubiquitous phenomenon in our daily lives. It is such a common occurrence that sometimes we are not even aware of it. Inspite of this till date, "yawning" still remains shrouded in a veil of mystery with no clear understanding of as to why or what are the mechanisms behind this activity. Provine, who is considered as the pioneer of yawning research, remarked in the late 1980s that "yawning may have the dubious distinction of being the least understood

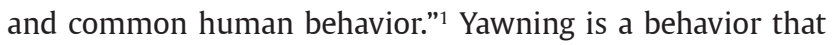
is observed across an evolutionarily diverse array of animals from fishes and birds to mammals and from the fetal to the old stages of life. In human beings, yawning has been observed as early as 12 weeks of fetal life. ${ }^{2}$ It is an phylogenetically old yet ontogenically new and stereotyped motor behavior that has not undergone much changes over the course of evolution. And any trait that has survived evolution is bound to have some significance for survival. It is also important to learn about the different mechanisms behind yawning because excessive yawning has been associated with certain conditions like narcolepsy, uremia, side effects of medications that are used to treat depression or anxiety such as selective serotonin reuptake inhibitors or even various forms of encephalopathy. In this review, we will try to explore the various mechanisms behind this seemingly ubiquitous phenomenon. The first documented account of yawning dates back to $400 \mathrm{BC}$ where Hippocrates wrote in de flatibus liber (a treatise on wind) that "yawning precedes a fever because the large quantity of air that has accumulated ascends all at once, lifting with the action of a lever, and opening the mouth; in this manner, the air can exit with ease. Like the large quantities of steam that escape from cauldrons when water boils, the accumulated air in the body is violently expelled through the mouth when the body temperature rises." ${ }^{3}$ Although as we shall see subsequently in this article in the absence of any teleological or scientific evidence, this notion was later discredited by the researchers in the late twentieth century, but the idea prevailed for a long time. A unanimously acceptable mechanism or teleological explanation to the phenomenon of 
yawning remains to be established, but various theories have been proposed by different groups of researchers over the last four decades. The present article tries to provide a narrative review of the existing knowledge we have on this subject.

\section{Functional Anatomy of Yawning}

Yawning is a stereotyped, reflexive motor activity which consists of a deep respiratory effort associated with extension of the neck and wide expansion of the jaw and subsequent contraction of the tongue. This may be associated with raising of the arms and muscular clenching of the extremities. ${ }^{4}$ The respiratory act comprises three distinct phases: (1) prolonged and deep open-mouth inhalation, (2) a brief acme, and (3) followed by a shorter exhalation. ${ }^{5}$ It is also often associated with lacrimation, either due to pressure on the lacrimal glands or of nervous stimulation or both. ${ }^{6}$ It is a complex yet very highly coordinated motor activity bringing together a flexion followed by an extension of the neck, a wide dilatation of the laryngopharynx with strong stretching of the diaphragm and antigravity muscles. And it is highly stereotypical because no environmental input changes the sequence of movements. Therefore, it often appears to be a semi-involuntary act, which once initiated cannot be suppressed, but its manifestations can be modified. ${ }^{7}$ The stereotypical nature of the yawn is consistent with the physiological property of reflexes being stereotypical. One of the indispensable concepts in neurophysiology is the notion of "moto-programs" which are sequences or algorithms fundamental to genesis of any motor activity. These have been attributed to certain "central pattern generators" in the central nervous system (CNS). It is now known that humans have certain built-in motor programs, which means for that particular activity, the sequence is fixed from beginning to end once it is started. ${ }^{8}$ The nature and as well as the duration of a yawn is almost consistent with a mean of just under 6 seconds. ${ }^{1,9}$

\section{Theories of Yawning}

Various theories have been put forward behind yawning. Some try to answer the purpose while others attempt to explain the mechanisms behind it. And both homeostatic roles and communicative role have been suggested. They range from respiratory, arousal, and thermoregulatory to its role as a component of action repertoire of advanced empathic and social skills. ${ }^{10}$

\section{Respiration and Yawning}

Because the act of yawn itself consists of a prominent respiratory pattern, the earliest reason proposed behind it was hypoxia. It has been held commonly that yawning is triggered when blood or brain oxygenation is insufficient, either due to hypoxia or due to hypercapnia. In fact as early as 1755, a noted author on medicine in the eighteenth century, Johan de Gorter, described in one of his books De Perspirationeinsensibili that yawning acts as a mechanism to accelerate blood flow and improve oxygenation of the brain in response to cerebral hypoxia. ${ }^{11}$
Yawning was thought to remove "bad air" from the lungs and increase circulation in the brain. ${ }^{12}$ It was more of a teleological argument and prevailed for almost two centuries. However, now it has been refuted by majority of the scientific communities. Blood levels of $\mathrm{O}_{2}$ and $\mathrm{CO}_{2}$ show little correlation with yawning. ${ }^{13}$ It was also observed in a study in the late 1980s that the yawning frequency was not affected by air mixtures containing either more than normal $\mathrm{CO}_{2}$ or even pure $\mathrm{O}_{2}$. However, more recent work in animal models lend some support in this hypothesis. Microinjections of L-glutamate, cyanide, and a nitric oxide-releasing compound (NOC12) into the medial parvocellular subdivision of paraventricular nucleus of the hypothalamus (PVN) in anesthetized, but spontaneously breathing rats produced a stereotypical yawning response. The authors suggested that the neurons in this area of the hypothalamus could have an oxygen-sensing mechanism, and diffusible NO could be a paracrine agent involved in the genesis of yawning response. ${ }^{14}$ Yawning is assumed to subserve important respiratory functions. Hyperinflation of the lungs as in yawning is an important stimulus for surfactant synthesis in the lungs. ${ }^{15}$ This is especially important for infants and might explain its presence even in fetal life. Yawning also enhances the dynamic lung compliance of lungs, that is, greater change in volume is possible per unit change of transpulmonary pressure. Additionally, it also improves the venous return to the heart.

\section{Arousal and Yawning}

The conditions during which yawning has been commonly observed are immediately before sleep, awakening from fully complete sleep, weariness, lack of stimulation, boredom, or any monotonous task. Medical conditions, such as multiple brainstem ischemic strokes, frontal lobe tumors, etc., could also cause excessive yawning. Increased frequency of yawning has also been observed in people intoxicated by Psilocybin mushrooms. ${ }^{6}$ All these scenarios described above have one common feature: lowered state of critical consciousness which implies a reduced state of normal, active awareness of being related to environment. It was suggested in the late 1980s that yawning actually is a complex arousal defense reflex from its close temporal occurrence with activities causing boredom or loss of interest, fatigue, and sleep. The center of this reflex was proposed to be the reticular formation of the brainstem, ${ }^{9}$ which we now know is the seat of the consciousness and also houses the various neural circuits implicated in sleep-wake states. ${ }^{8,16}$ Even in infants and children (aged 6-34 months), the most common context of yawns as recorded by their mothers was on awakening after morning or afternoon naps, suggesting its close temporal association with sleep and wakefulness. ${ }^{17}$ This proposition was later supported by observations in studies on human subjects where physiological variables associated with aroused state like an increased heart rate, increased skin conductance and $\alpha$ waves on electroencephalogram were studied in relation to yawning. The $\alpha$-waves on EEG are most marked when the person is awake but relaxed and the eyes are closed. ${ }^{16,18}$ This correlates with the experiential feeling of comfort or relaxation during a yawn. Studies in the 
last decade have yielded that EEG changes found postyawning were consistent with those observed intake of caffeine, which is a known stimulant of CNS. ${ }^{19,20}$ In 2011, a group of researchers showed that heart rate significantly increased at the peak of a yawn $(p<0.001), 10$ seconds $(p=0.002)$ and 15 seconds $(p<0.001)$ after yawning as compared with the resting values. ${ }^{21}$ Also, the stretching of the muscles around the jaw and neck during could also compress the carotid bodies and baroreceptors which are located in the major blood vessels of the region. This would trigger a downstream alteration in the circulation by altering the resting vasomotor tone on the arteries. ${ }^{6,15}$ This might possibly increase cerebral blood flow too, contributing to enhanced alertness.

\section{The Ear and Yawning}

The eustachian tube is a channel that connects the middle ear cavity with the pharynx. This plays vital role when there is a change of air-pressure on either side of the tympanic membrane as in rapid ascent or descent, as observed in take-off or landing of aeroplanes, or diving, for example. The pressure difference causes the tympanic membrane to bulge outward in the former and pulled inward in the latter scenarios, often causing discomfort and pain in many people. ${ }^{22}$ Yawning causes an opening and closing of the pharyngeal end of the eustachian tube, thus equilibrating the pressure. Therefore, the mechanics associated with yawning can help relieving these symptoms.

\section{Thermal Homeostasis and Yawning}

There is yet another proposed function of yawning is maintaining of thermal homeostasis, especially the temperature of the head. Researchers have proposed that yawning "cools the brain." Studies in clinical settings suggested that an increased occurrence of yawning is observed in pathological states where there was a sudden increase in the core temperature of the body as in epilepsy, migraine, multiple sclerosis, etc. The episodes of symptoms subsided following yawning. ${ }^{23-25}$ The authors have even contemplated considering pathological yawning as a part of the symptomatology of these diseases. Further evidence in this regard was provided by a series of animal experiments in mice and parakeets where the cortical brain temperature was more before and less after yawning. ${ }^{26,27}$ In an interesting study done on human volunteers using warm-pack and ice-pack applied to the forehead, the researchers observed that there was an increase in yawning when warm packs were applied..$^{28}$ The premise of this heat-loss theory can be understood by considering the various concepts of heat dissipation from the body. Heat can be lost when there is an increased blood flow which takes away the heat from the core to the surface or when there is an enhanced loss of air from the body as deep breathing. ${ }^{16}$ Although brain is one of the most metabolically active organs of the body; however, it still remains to be proved conclusively that higher metabolic rates can increase the internal temperature of the region. This is one of the questions that the authors could not explain. The contraction and relaxation of a variety of the muscles of the face and neck during a yawn, increases the facial blood flow which aids in dissipation of heat. Concomitant stretching of the lower extremities often observed while yawning contracts muscles like the soleus, the "peripheral heart" which in turn increases the venous return to the right chambers of the heart, thus increasing the cardiac output and consequently increasing cerebral blood flow. ${ }^{29}$ Heat is also lost as yawning by itself is an act of deep and prolonged respiration. Interestingly much before we had these modern methods of quantifying metabolism or blood flow, a similar theory was also purposed by an Italian physician Santorio Santori in as early as 1634 . He proposed an analogy between yawning and limb extension after sleep with that of a rooster that flapping its wings before it starts to sing. Both of these activities, he had suggested increased perspiration. ${ }^{30}$

\section{Emotional Yawning}

A specific type of yawning has also been observed in relation to certain emotional states and described by ethologists as "emotional yawns." Although not much comprehensive in its explaining in humans, this theory states that yawn is generated by the paleomammalian brain and helps to pacify after stress. Observations in its favor have been drawn mainly from observations in dogs and caged chimpanzees, yawning more during stressful times. A type of yawning has also been associated with sexuality in dominant male macaques, who yawn repeatedly before mating, as if to assert their dominance in the group. And interestingly, this type of yawning disappears following castration and reappears if testosterone is injected. ${ }^{31}$

\section{Is There a Biochemical Basis?}

Evidence of a possible biochemical basis was put forward primarily from animal experiments, primarily in the last decades of the previous century. Dopaminergic and Cholinergic agonists, ACTH-MSH and oxytocin, were observed to produce yawning in rats. Intraventricular injection of ACTH, $\alpha-\mathrm{MSH}$, and oxytocin was found to induce yawning and stretching in these animals. Dopaminergic and cholinergic antagonists were found to inhibit the same, thereby suggesting a possible role of these two compounds too. ${ }^{7,32,33}$ One of the prominent biochemical theories of yawning is Thompson's Cortisol hypothesis which proposes that cortisol levels are elevated during yawning episodes. Evidence in favor of this hypothesis was provided when researchers found higher levels of stress hormones particularly cortisol, was recorded in the saliva of human subjects following yawning. ${ }^{6}$ With regard to neurochemistry of yawning, the most comprehensive model is centered around PVN of the hypothalamus. It suggests that oxytocinergic neurons originating there and projecting to extra hypothalamic brain areas mediate the expression of yawning in animals in most circumstances. Activation of these neurons in the PVN by dopamine receptor agonists, excitatory amino acids, and oxytocin results in yawning and 
their inhibition by opioids, for example, endogenous opioids like enkephalins prevent the behavioral expression. ${ }^{34}$

\section{Decoding the Contagiousness of a Yawn: The Mirror Neuron System}

The social contagiousness of a yawn is one of the most common experiences of our daily lives. Whether we see other people actually yawning or videos of people yawning or even read and hear repeatedly about yawning, it seems to be transmitted to us and we too tend to yawn very often. In fact, it would not be surprising if the reader of this article gives out a yawn or two by the time he or she finishes reading it. There are two basic ways by which yawning can be elicited: thoughtful preoccupation and subconscious or unconscious imitation..$^{29}$ This particular and rather peculiar property of a yawn is now considered to be an evolutionarily derived skill of social empathy.

A study published in 2011 on yawning in 109 healthy adult volunteers of various nationalities in their natural work environments concluded that social bond greatly influenced the bouts of yawning between the yawner and the observer (in which it was triggered as a response). It significantly increased from strangers, acquaintances, close friends to kin $(p<0.001)$. The authors concluded that yawning and social empathy are closely linked. ${ }^{35}$ More studies exploring this social aspect have provided further evidence. Yawning episodes were significantly lesser in schizophrenic patients ${ }^{36}$ and in autistic children as compared with age and sex-matched controls when similar stimuli like yawning videos were shown to them. ${ }^{37}$ Both of these scenarios depict patients in whom social skills and understanding are deficient. Researchers have also suggested that even in healthy children, contagious yawning can occur in children only after 4 to 5 years of age because until this age, neural mechanisms implicated in social skills are still under the process of development..$^{38} \mathrm{~A}$ study done on chimpanzees yielded some interesting results. A group of 23 adult chimpanzees were observed for contagious yawning while viewing the videos of yawning movements of the mouth of same species and different species, that is, humans. They authors observed that yawning responses were more in the former case. Although, the small sample size was a major limitation in the study. Nonetheless, the study points out, at least qualitatively, that yawning must have a role in social communication, even in other mammals. ${ }^{39}$

Neuroimaging studies investigating the physiological basis of yawning reported that higher functional magnetic resonance imaging activations in response to contagious yawning have been observed in posterior cingulate area, ${ }^{40}$ bilateral superior temporal sulcus, ${ }^{41}$ or ventro-medial prefrontal cortex. ${ }^{42}$

The neural basis of yawning is now attributed to a system of neurons in the brain called as "mirror neurons." Mirror neurons are one of the most enigmatic set of neurons that hold the key to evolution of human civilization. They represent a distinctive class of neurons that discharge both when an individual executes a motor act and when he observes another individual performing the same or a similar motor act. These neurons were first discovered in monkey's brain. ${ }^{44}$ The human mirror-neuron system consists of a network involving the following areas: supplementary motor area, primary somatosensory cortex, inferior parietal cortex, and ventral premotor area. Additionally, neurons having mirror properties have also been discovered in Broca's area, Wernicke's area, Fusiform Gyrus, Angular gyrus, and Primary motor cortex. ${ }^{44,45}$ These system of neurons are now known to be the fundamental seat of human emotions like empathy at the cellular level..$^{46-48}$ Thus, this provides the physiological basis of the social contagiousness of occurrence of yawning.

\section{Recent Trends: Is There a Link with Cortical Motor Excitability?}

A research team at the University of Nottingham investigating in the field of cognitive neuropsychology have rather come up with interesting results. They conducted a study on 36 volunteers showing them video clips of another individual yawning and were told to either resist yawning or allow themselves to yawn. They were observed and videoed throughout. Transcranial magnetic stimulation was concomitantly used to quantify motor cortical excitability and physiological inhibition for each participant. They demonstrated that the participants who resisted yawning had increased the urge to yawn and altered how yawns were expressed (i.e., complete yawns or stifled yawns). They made two important observations. First, that during yawning there is an increased excitability of the cells of primary motor cortex and/or decreased physiological inhibition. And even suggested a possible link with a wide range of clinical conditions where echophenomena is observed like epilepsy, dementia, autism, and Tourette syndrome and also have similar physiological attributes like increased cortical excitability. And second, the propensity of contagious yawning is highly individualized. ${ }^{49}$

\section{Yawning Modifiers}

The occurrence of contagious yawning and the factors which might trigger yawning have already been discussed above. They could range from alterations in sleep-arousal system to emotional factors. However, one of the latest works shows that the occurrence of a yawn could be modified experimentally by changing the temperature around the neck. A recent study published in 2019 in which participants were asked to hold a warm $\left(46^{\circ} \mathrm{C}\right)$, cold $\left(4^{\circ} \mathrm{C}\right)$, or room temperature $\left(22^{\circ} \mathrm{C}\right)$ pack firmly to their neck, just over their carotid arteries, for a period of 5 minutes prior to watching a contagious yawning stimulus reported interesting findings. More than $80 \%$ of the participants reported the urge to yawn with warm packs and less than half (48.5\%) with the cold packs. This study further supports the thermoregulation hypothesis associated with yawning. While other research works as discussed in the previous section have also proposed that the physiological tendency of yawning is highly individualized..$^{50}$ 


\section{Conclusion}

The phenomenon of yawning has fascinated the human beings for ages and the truth is, the complete neurobiology behind it is still unknown. ${ }^{51}$ The unique, universal, ephemeral, and stereotypical qualities of yawning have invited boundless speculation about its evolution, function, and significance from the scientific community. With more and more evidences and experiments with newer methods like neuroimaging, older concepts have changed and newer theories about various aspects have emerged. However, its full neurophysiological mapping is yet to be completed.

\section{Funding}

None.

\section{Conflict of Interest}

None declared.

\section{Acknowledgments}

The authors gratefully acknowledge the various researchers who have explored the subject.

\section{References}

1 Provine RR. Yawning as a stereotyped action pattern and releasing stimulus. Ethology 1986;72:109-122

2 Walusinski O. [Yawning: from birth to senescence]. Psychol Neuropsychiatr Vieil 2006;4(1):39-46

3 de Mercy FC, Oeuvres d'Hippocrate. Traité de la MaladieSacrée, des Vents ou des Fluxions. Paris: BéchetJeune; 1831359

4 Dolkart KM. A conjecture as to the physiological origins of yawning. Int J Appl Basic Med Res 2017;7(2):148

5 Chouard $\mathrm{CH}$, Bigot-Massoni D. Mécanismeset roles physiologiques du bâillement. AnnOto-Laryng 1990;107:145-153

6 Dhungat JV. Yawning: behavior and physiology. J Assoc Physicians India 2016;64(7):106

7 Alóe F. Yawning. Arq Neuropsiquitar 1994;52(2):273-276

8 Kalat JW, Biological Psychology. 10th ed. Boston, MA: Wadsworth Cengage Learning; 2009

9 Askenasy JJ. Is yawning an arousal defense reflex? J Psychol 1989;123(6):609-621

10 Guggisberg AG, Mathis J, Schnider A, Hess CW. Why do we yawn? Neurosci Biobehav Rev 2010;34(8):1267-1276

11 Walusinski 0 . The mystery of yawning in physiology and disease: Foreward. Front Neurol Neurosci 2010;28:X-XIV

12 Schiller F. Yawning? J Hist Neurosci 2002;11(4):392-401

13 Bijlani RL, Manjunatha S, Understanding Medical Physiology. 4th edition. New Delhi: Jaypee Brothers Medical Publishers; 2011

14 Kita I, Sato-Suzuki I, Oguri M, Arita H. Yawning responses induced by local hypoxia in the paraventricular nucleus of the rat. Behav Brain Res 2000;117(1-2):119-126

15 Pal GK, Pal P, Nanda N, Comprehensive Textbook of Medical Physiology. 2nd edition. New Delhi: Jaypee Brothers Medical Publishers; 2019

16 Barrett KE, Barman SE, Botaino S, Brooks HL, Eds. Ganong's Review of Medical physiology. 25th edition. Noida: McGraw Hill Education (India) Private Limited; 2012

17 Millen A, Anderson JR. Neither infants nor toddlers catch yawns from their mothers. Biol Lett 2011;7(3):440-442

18 Sircar S, Principles of Medical Physiology. 2nd edition. Noida: Thieme Publishers; 2014

19 Barry RJ, Rushby JA, Wallace MJ, Clarke AR, Johnstone SJ, Zlojutro I. Caffeine effects on resting-state arousal. Clin Neurophysiol 2005;116(11):2693-2700
20 Gupta S, Mittal S. Yawning and its physiological significance. Int J Appl Basic Med Res 2013;3(1):11-15

21 Corey TP, Shoup-Knox ML, Gordis EB, Gallup GG Jr. Changes in physiology before, during, and after yawning. Front Evol Neurosci 2012;3:7

22 Dhingra PL, Dhingra S, Diseases of the Ear, Nose and Throat and Head, Neck Surgery. 6th edition. New Delhi: Elsevier; 2014

23 Postert T, Pöhlau D, Meves S, Nastos I, Przuntek H. Pathological yawning as a symptom of multiple sclerosis. J Neurol 1996;243(3):300-301

24 Yankovsky AE, Andermann F, Dubeau F. Post-ictal forceful yawning in a patient with nondominant hemisphere epilepsy. Epileptic Disord 2006;8(1):65-69

25 Jacome DE. Compulsive yawning as migraine premonitory symptom. Cephalalgia 2001;21(5):623-625

26 Shoup-Knox ML, Gallup AC, Gallup GG, McNay EC. Yawning and stretching predict brain temperature changes in rats: support for the thermoregulatory hypothesis. Front Evol Neurosci 2010;2:108

27 Gallup AC, Miller ML, Clark AB. Yawning and thermoregulation in budgerigars (Melopsittacusundulatus) Anim Behav 2009;77:109-113

28 Gallup AC, Gallup GG. JrYawning as a brain cooling mechanism: Nasal breathing and forehead cooling diminish the incidence of contagious yawning. Evol Psychol 2007;5:92-101

29 Lehmann HE. Yawning. A homeostatic reflex and its psychological significance. Bull Menninger Clin 1979;43(2):123-126

30 Santori S, De Statica Medicinaet de Responsionead Staticomasticem. Aphorismorum Sectionibus Septem Comprehensa, Italy: MA Brogiollo; 163471

31 Walusinski O, Why do we yawn? Past and current hypotheses. Chapter 16. In: Shoja MM, Agutter PS, Tubbs RS, Ghanei M, Ghabili K, Harris A, Loukas M, eds. Hypotheses in Clinical Medicine. France: Nova Science Publishers, Inc; 2013:245-56

32 Lobo LL, Neumann BG, Eidman DS, Tufik S. Effects of REM sleep deprivation of ACTH-induced yawning. Pharmacology 1990;40(3):174-178

33 Metis MR, Argiolas A, Gessa GL. Apomorphine-induced penile erection and yawning: site of action on the brain. Brain Res 1987;398:259-265

34 Krestel H, Bassetti CL, Walinski O, et al. Yawning: its anatomy, chemistry, role, and pathological considerations. Available at: Available at: http://www.baillement.com/recherche/yawning_pgn2018.pdf. Accessed May 25, 2020

35 Norscia I, Palagi E. Yawn contagion and empathy in Homo sapiens. PLoS One 2011;6(12):e28472

36 Haker H, Rössler W. Empathy in schizophrenia: impaired resonance. Eur Arch Psychiatry Clin Neurosci 2009;259(6):352-361

37 Senju A, Maeda M, Kikuchi Y, Hasegawa T, Tojo Y, Osanai H. Absence of contagious yawning in children with autism spectrum disorder. Biol Lett 2007;3(6):706-708

38 Saxe R, Carey S, Kanwisher N. Understanding other minds: linking developmental psychology and functional neuroimaging. Annu Rev Psychol 2004;55:87-124

39 Campbell MW, de Waal FB. Ingroup-outgroup bias in contagious yawning by chimpanzees supports link to empathy. PLoS One 2011;6(4):e18283

40 Platek SM, Mohamed FB, Gallup GG Jr. Contagious yawning and the brain. Brain Res Cogn Brain Res 2005;23(2-3):448-452

41 Schürmann M, Hesse MD, Stephan KE, et al. Yearning to yawn: the neural basis of contagious yawning. Neuroimage 2005;24(4):1260-1264

42 Nahab FB, Hattori N, Saad ZS, Hallett M. Contagious yawning and the frontal lobe: an fMRI study. Hum Brain Mapp 2009;30(5):1744-1751 
43 Arnott SR, Singhal A, Goodale MA. An investigation of auditory contagious yawning. Cogn Affect Behav Neurosci 2009;9(3):335-342

44 Acharya S, Shukla S. Mirror neurons: Enigma of the metaphysical modular brain. J Nat Sci Biol Med 2012;3(2):118-124

45 Rizzolatti G, Fogassi L, Gallese V. Neurophysiological mechanisms underlying the understanding and imitation of action. Nat Rev Neurosci. 2001;2:661-70. Acharya S, Shukla S. Mirror neurons: enigma of the metaphysical modular brain. J Nat Sci Biol Med 2012;3(2):118-124

46 Decety J, Jackson PL. The functional architecture of human empathy. Behav Cogn Neurosci Rev 2004;3(2):71-100
47 Gallese V, Goldman A. Mirror neurons and the simulation theory of mind-reading. Trends Cogn Sci 1998;2(12):493-501

48 Gallese V. The "shared manifold" hypothesis: from mirror neurons to empathy. J Conscious Stud 2001;8:33-50

49 Brown BJ, Kim S, Saunders H, et al. A neural basis for contagious yawning. Curr Biol 2017;27(17):2713-2717.e2

50 Ramirez V, Ryan CP, Eldakar OT, Gallup AC. Manipulating neck temperature alters contagious yawning in humans. Physiol Behav 2019;207:86-89

51 Calder C. What is it about yawning? The conversation. Available at: https://theconversation.com/what-is-it-aboutyawning-98292. Accessed May 25, 2020 